\title{
O Premio Jules Verne na literatura galega. A necesidade da inclusión das obras premiadas nas aulas galegas
}

\author{
Marta Neira Rodríguez \\ [Recibido, 15 setembro 2019; aceptado, 11 decembro 2019] \\ http://dx.doi.org/10.15304/bgl.55.6275
}

RESUMO Repaso á traxectoria do Premio Jules Verne, convocado por Edicións Xerais de Galicia, na Literatura Infantil e Xuvenil galega. $\mathrm{Nel}$ darase conta dos autores e autoras que foron galardoados, das temáticas abordadas e doutros trazos que o definen. Farase especial fincapé na presenza das voces femininas nese galardón.

PALABRAS CHAVE: aulas galegas; Literatura Infantil e Xuvenil galega; Premio Jules Verne; premios; Xerais; voces femininas.

ABSTRACT A review of Jules Verne Award's pathway, issued by Edicións Xerais de Galicia, in Galician Children's and Young Adults Literature. It will focus on award-winning authors, topics addressed and another defining features. Special attention will be given to the presence of female voices in this prize.

KEYwORDS: Galician classrooms; Galician Children's and Young Adults Literature; Jules Verne Award; prizes; female voices.

\section{Introdución}

No ano 2005 Edicións Xerais de Galicia e a Fundación Caixa Galicia convocaban o Premio Fundación Caixa Galicia de Literatura Xuvenil coa pretensión de que fose unha plataforma coa que os escritores e as escritoras puidesen achegar ao sistema literario galego obras coas que "conquistar un lectorado con temas e linguaxe acordes coa súa cultura" (Roig, 2015: 290).

Dotado inicialmente con $7.500 €$, este premio, que galardoaba orixinais inéditos escritos en lingua galega e que se fallaba, xunto cos Premios Merlín e Xerais de Novela, no transcurso da Cea Xerais, pasou a convocarse no 
ano 2011 coa denominación Premio Fundación Novacaixagalicia-Claudio San Martín de Literatura Xuvenil e cun cambio de periodicidade (pasaba a ser bianual). Con todo, nos anos 2012 e 2013 o premio non se convocou e non foi até 2014 cando reapareceu co nome co que actualmente se coñece: Premio Jules Verne de literatura xuvenil, denominación que tamén levou parella unha muda na dotación económica (a partir dese momento a contía é de 10.000 euros).

Os xurados, compostos en todas as edicións por diferentes profesionais da cultura galega e representantes do lectorado mozo (tal como se recolle paratextualmente na primeira edición da obra gañadora e pode seguirse Roig, 2006-2017), concedéronlle os galardóns ás seguintes obras: $A$ cova das vacas mortas (2006), de Santiago Jaureguizar; Illa Soidade (2007), de An Alfaya; A cabeza de Medusa (2008), de Marilar Aleixandre; As de bolboreta (2009), de Rosa Aneiros; Febre (2011), de Héctor Carré; O Gran Reino (2014), de Eduardo Santiago; Europa Express (2015), de Andrea Maceiras; Xa non estou aqui (2016), de Iria Misa; Ceiba de Luz (2017), de Manuel Lourenzo González; Aplicación instantánea (2018), de Carlos Negro, e Os corpos invisibles (2019), de Emma Pedreira.

\section{Autoría e temáticas das obras gañadoras}

O primeiro gañador deste premio foi Santiago Jaureguizar (Bilbao, 1965), autor pertencente á Xeración dos 90 que xa tiña achegado diferentes títulos á Literatura Infantil e Xuvenil galega, tal como pode seguirse en Roig (2015) e Roig (1995-2009).

Na obra gañadora, A cova das vacas mortas, partindo de elementos da historia recente (Segunda Guerra Mundial), recrea o proceso de maduración do protagonista, Xoel, un adolescente que reside en Negueira de Muñiz, nunha comuna hippy creada por naturalistas alemáns, nos anos setenta. O mozo é o encargado do coidado da nai e do avó, este último enfermo de alzhéimer e responsábel de que Xoel, a partir da relación avóneto, descubra un pasado familiar vinculado co nazismo e se enfronte a unha loita entre os sentimentos polas persoas e as ideoloxías que representan, circunstancia marcada aínda máis pola personaxe da moza Iria, contrapunto do protagonista. 
O relato, cuxa cuberta, ilustrada por Miguel A. Vigo, presenta en primeiro plano unha antiga cámara de vídeo e uns negativos que anticipan a vinculación do relato co cinema, presenta unha axeitada combinación de ritmo e intriga, cunha prosa áxil e gran naturalidade dos diálogos cos que se pretende conectar cos intereses do lectorado adolescente.

Unha muller, An Alfaya, nome literario de $\mathrm{M}^{\mathrm{a}}$ de los Ángeles Alfaya Bernárdez (Vigo, 1964), foi a galardoada na edición de 2007 pola novela realista Illa Soidade. A autora, igual que Jaureguizar pertencente á Xeración dos 90, achégalle ao lectorado o tema da intolerancia (Pena, 2007) e a realidade de moitos indixentes. A protagonista é Lucía, unha moza que inicia os seus estudos universitarios e, na viaxe en tren á Cidade Universitaria á que se dirixe, lembra a relación que estabeleceu cando tiña dezaseis anos cun grupo de vagabundos que frecuentaban unha praza próxima á casa e ao negocio familiar, máis concretamente a súa relación con Soidade (Soa), a primeira indixente en instalarse na praza dos Mistos.

Por medio dunha voz narradora en primeira persoa, Lucía, e os fragmentos do "Diario de outono" de Soa, cuxos fragmentos se intercalan cos recordos da moza (a Mirona, como a bautizaron os mendigos), vaise coñecendo a vida de Soa e as razóns polas que chegou á mendicidade, entre as que se pode atopar un fracaso matrimonial e a busca dun amor perdido co que entrou en contacto en París.

A ilustración da cuberta, de Antonio Seijas, amosa, como se sinalou en Roig (2008), a realidade de moitas cidades dun xeito moi poético, pois presenta un banco, como calquera outro que se pode atopar nunha rúa, no medio da auga, un mar que, xogando coas diferentes acepcións deste termo, podería identificarse cun océano de soidade urbana.

Marilar Aleixandre (Madrid, 1947), escritora pertencente á Xeración do 68 (Roig, 2015), foi a terceira en recibir o premio no que se detén este traballo por unha obra que, como sinalou Soto (2008), se pode incluír no metaxénero das "novelas de instituto": A Cabeza de Medusa. Incluída na listaxe The White Ravens 2009 e Premio Frei Martín Sarmiento 2010, este relato achégase a un tema pouco ou nada tratado na Literatura Infantil e Xuvenil galega como é o das consecuencias dunha violación sexual e, por desgraza, moi vixente na sociedade actual (pénsese no coñecido caso da Manada ou noutros que seguen o horrendo ronsel deste). 
A cabeza de medusa está estruturada en tres partes, encabezadas por senllas referencias a producións artísticas do mito que lle dá nome, e presenta múltiples referencias literarias, musicais e fílmicas da cultura adolescente, que teñen a dobre funcionalidade de crear verosimilitude e provocar no lectorado unha conexión empática e de identificación coa novela, tal e como sinalou Ferreira Boo (2012). Baseada en feitos reais, segundo ten sinalado a autora nalgún acto público, achégase ao sufrimento de dúas mozas, Sofía e Lupe, despois de seren violadas (presión social, silencio sobre o acontecido etc.) e ofrece diferentes perspectivas deste feito que evitan tomar partido das posturas existentes.

A novela, que actualiza a lenda de Medusa, que se instala no discurso e que, como sinalou Soto (2008), serve como metáfora das interpretacións negativas da feminidade, salienta pola temática tratada, pola prosa, directa e obxectiva, e polo desenvolvemento da trama. É, seguindo a Puñal (2009: 9), unha narración que atrapa e sintetiza unha tripla violación: a física, a cultural e a social, e, como sinalou Senín (2009: 81), "a opinión valente dunha persoa que coa súa escrita toma partido pola vida, polo respecto sagrado da persoa, pola liberdade individual”.

Novamente unha muller, neste caso Rosa Aneiros (Meirás-Valdoviño, Ferrol, 1976), foi a gañadora da seguinte edición do certame. Con As de bolboretas, incluída na listaxe The White Ravens en 2010, a autora pertencente á denominada Xeración Google, e con varios títulos publicados con anterioridade (véxase Roig, 1999-2010), aborda un amplo abano de problemas sociais, tales como a soidade dos maiores, os malos tratos, a ideoloxía machista e dominadora, a inmigración etc. Faino por medio de breves capítulos nos que un narrador omnisciente presenta a historia dunha ampla galería de personaxes ${ }^{1}$ que teñen en común o feito de frecuentaren un espazo concreto e cotián, a cafetaría Luzada, rexentada por Patricia, a persoa que distribúe afectos e cunha posición activa nas relacións que se presentan.

1 Entre as historias e personaxes que se atopan están as de Manuel e o seu avó; Lola e Eusebio, un matrimonio da terceira idade que se enfronta á soidade e á vellez; lqbal, un mozo paquistaní que abandona Londres tras os atentados no metro en 2005; Aysel, unha kurda que expresa a súa rebeldía pola indiferenza internacional perante a represión do seu pobo por parte do goberno turco; os alpinistas do monte Gurugú, dous mozos nixerianos que tentan atravesar o valado da fronteira de Melilla para poder reunirse coa súa tía, que agarda todos os días no bar unha chamada que confirme a súa chegada a Galicia; ou Paco e Adolfo, dous homes que se comportan mal coas súas respectivas mulleres. 
Dende esa localización espacial, eixe central da historia, pois dese bar parten as redes de relacións entre personaxes de diversas procedencias e culturas, artéllase unha escolma de vidas coa intención de plasmar a misteriosa interrelación dos diferentes feitos e historias que conflúen nese pequeno bar cun contexto complexo e global, consonte ao significado do efecto bolboreta que evoca o título e que a partir dun proverbio chinés expresa a interconexión e a fraxilidade. Unha escolma á que se accede por medio dun narrador omnisciente que tamén combina estratexias narrativas e cinematográficas, nas que se alternan os ángulos e planos panorámicos con primeiros planos, cargados de subxectivismo (Soto, 2010: 80-81). A narración ofrece a estrutura dun crebacabezas, sen fixación de historias nin de personaxes, senón de situacións problemáticas da sociedade actual, dende a multipluralidade e abertura temática.

A ilustración da cuberta, que se corresponde cunha composición fotográfica de Miguel A. Vigo, adianta a multiculturalidade presente no relato grazas a unha fachada dun edificio con ventás en cuxo baixo se pode ler Luzada, á parte de moitos outros nomes de lugares afastados da realidade galega

Na nova andaina que o premio iniciou no ano 2011 a obra premiada foi Febre, do guionista e director de cine Héctor Carré (A Coruña, 1960), un autor descoñecido na Literatura Infantil e Xuvenil galega até ese momento e que, por idade, máis tamén por características, se encadra na Xeración $\operatorname{dos} 90$.

A novela, que mereceu o Premio Fervenzas Literarias ao mellor libro xuvenil no ano da súa publicación, é de marcado estilo cinematográfico (influencia da formación do autor) e remite á época da Segunda Guerra Mundial e á explotación das minas de volframio en Galicia (concretamente na vila de Noia), así como á loita dunha muller por facerse coas rendas do seu destino.

Estruturada en capítulos organizados en secuencias, que semellan escenas cinematográficas, e situada a inicios dos anos corenta do século XX, o lectorado coñece a grandes trazos a evolución da Segunda Guerra Mundial, na que España se mantivo neutral e non belixerante, mais tamén a realidade dunha moza idealista, Carmucha, que loita pola ruptura de 
barreiras e trabas igual que "unha afouta heroína para acadar a súa independencia e loitar pola xustiza e os dereitos dos marxinados sociais, chea de xenerosidade e que por veces raia na irresponsabilidade" (Ferreira Boo, 2017). Unha protagonista que non dubida en facerse contrabandista e organizar unha banda coa que acadará sona de xusticeira, e que mesmo será temida e respectada, mais que terá que marchar do país por mor do asasinato dun home, quen a viola non só física senón tamén simbolicamente.

Tal como sinalou Soto (2011: 50; 2015: 64), unha "novela de aventuras, de acción, de amor, de espías, de ronsel histórico galego e retrato social, de realidade cotiá" que se pode adscribir, como recolleu Ferreira Boo (2017), ao xénero negro, pero tamén á novela da memoria, ao recrear e recuperar os tempos da posguerra e da Segunda Guerra Mundial en Galicia. Unha obra ben documentada e novidosa polo "tratamento da era do volframio por vez primeira na Literatura Infantil e Xuvenil galega; a perspectiva dun narrador omnisciente que deixa fluír a conciencia das protagonistas femininas e dos personaxes da súa contorna; e o multiperspectivismo enfiado coa distancia espazo-temporal” (Fernández Vázquez, 2015: 206).

En 2014, o gañador do Premio Jules Verne foi Eduardo Santiago (Pontevedra, 1964), un autor tamén descoñecido na Literatura Infantil e Xuvenil até ese momento, por O Gran Reino (2014). Pertencente igual que o anterior premiado, á Xeración dos 90, Santiago achégase nesta novela ao trastorno alimentario da protagonista, Gala, unha rapaza que está cursando segundo da ESO, cun forte espírito competitivo e cunha grande intelixencia.

A protagonista inicia un proceso de illamento, que a leva a refuxiarse na lectura compulsiva e a convencerse de que só pode acceder ao mundo de Margonia, un complexo universo imaxinario, "unha metáfora da percepción distorsionada da realidade baseada no concepto dos universos refractarios" (Mociño, 2014), se non inxire ningún tipo de alimento. Esta situación provoca que a familia busque a axuda de profesionais, mais a intelixencia da moza fai que os engane até o punto de que o seu deterioro físico a leve á inclusión nunha unidade psiquiátrica. Parella á realidade desenvólvese o mundo imaxinario da moza no que terá que lograr unir o Gran Reino a partir de catro amuletos.

A novela, que segue a liña temática do relato de fronteira "Coma o pato Donald”, de Fran Alonso, inserido en Males de cabeza (Xerais, 2001), 
achégase a un asunto novidoso no que salienta o diálogo entre realidade e fantasía, a habelencia para achegarse aos trastornos psicolóxicos, cuestionar a percepción social da loucura e propiciar a reflexión sobre as moitas vías que poden seguir os conflitos internos para manifestarse nos comportamentos individuais.

O Gran Reino presenta na cuberta unha imaxe de Antonio Seijas, realizada con ferramentas de pintura dixitais, na que se amosa a protagonista do relato coa cara iluminada polo debuxo duns seres indescifrábeis: formas amarelas que a rodean e que parecen emanar do mundo interior no cal está sumida. As ilustracións interiores de Raquel Santiago son debuxos esquemáticos realizados en grafito, esquemas rápidos de criaturas descoñecidas.

As mulleres tomaron novamente as rendas do premio nos anos 2015 e 2016. Foron dúas escritoras novas, Andrea Maceiras (A Coruña, 1987) e Iria Misa (Gondomar, 1983), ambas as dúas pertencentes á denominada Xeración Google (Roig, 2015), as gañadoras do Jules Verne, respectivamente, por Europa Express e Xa non estou aquí.

A primeira delas, Andrea Maceiras, fíxose co galardón cunha novela coral, de viaxes e aventura psicolóxica que se achega ao proceso de maduración de sete personaxes (Nico, Mía, Óscar, Piero, Beatriz, Aroa e Xacobe). A historia aséntase nas lembranzas de Nico, quen, a partir dun feito fortuíto, recorda a viaxe feita por Europa cos seus compañeiros ao rematar o Bacharelato.

Dividida en tres partes, a primeira, "Sen notificación de recibo", serve para a presentación dos personaxes e sitúase no mes de agosto de dez anos atrás, cando eran adolescentes, e a vida actual de todos eles, marcada polo falecemento dun dos compañeiros de viaxe, a maduración que ese transo supuxo e o distanciamento del derivado e que fixo minguar a amizade que os unía. A segunda, "Xiro postal", céntrase na tentativa de Nico de reconstruír, grazas ás opinións de Mía, Beatriz, Óscar e Piero, a verdadeira relación que existía entre Aroa e Xacobe e que foi capturada por casualidade nunha fotografía. A terceira, "Franqueo en destino", coma a primeira, oscila entre os saltos ao pasado (aos últimos días da viaxe por Europa) e o momento presente (a reunión que prepara Nico na súa casa e de Aroa) 
para tentar comprender o comportamento do amigo falecido durante os derradeiros días da viaxe e a causa real da súa morte.

A montaxe fotográfica da cuberta, de Antonio Seijas, amosa unha parella bicándose, ao tempo que anticipa a viaxe por Europa no Interrail dos protagonistas que descubrirán a liberdade (simbolizada tamén polos paxaros na montaxe fotográfica) e a complexidade das relacións persoais.

A segunda das autoras, Iria Misa, debutou na Literatura Infantil e Xuvenil galega cun tema de plena actualidade na sociedade galega, pois, de maneira fortuíta, a publicación da obra de Misa saíu a lume pouco tempo despois da desaparición de Diana Queer.

Ao longo de vinte e seis capítulos titulados, enmarcados nun "Preámbulo" (ao que lle antecede un breve texto no que os termos "morte", "dor" e "vida" anticipan algúns trazos da intriga da novela) e un "Epílogo", o lectorado coñece os feitos que rodean a misteriosa desaparición de Ánxela, unha moza que repite primeiro de bacharelato e que no novo curso escolar abandona as amizades de sempre e entra en contacto cos Murnios, un gru40 po, formado por María, Carlos, Gabriel e os irmáns Leirós, cuxos hábitos, distintos aos doutros compañeiros, finalmente non darán en nada bo.

Dende diferentes puntos de vista (o de Ánxela, pero tamén os dos seus pais ou, sobre todo, os dos Murnios) o lectorado é quen de configurar o crebacabezas que supón a estraña desaparición dunha rapaza, principal asunto da novela. Con todo, Xa non estou aquíe unha novela que fala da incomprensión familiar, da necesidade de pertencer a un grupo, da soidade, das drogas, da falta de personalidade, da autoestima, da aparente desgana dos máis novos, da necesidade de experiencias vitais de risco para saír do cotián, do amor, da fidelidade, da homosexualidade e de como esta é vista polos outros ou mesmo por un mesmo.

A cuberta do libro de Miguel A. Vigo funde imaxes nunha colaxe dixital: unha ruleta en primeiro plano, siluetas humanas no plano medio e un bosque de fondo polo que entra a luz na parte superior en tons ocres e laranxas.

Nos últimos tempos o galardón recaeu en Manuel Lourenzo González (Vilaboa, Pontevedra, 1955), un escritor pertencente á Xeración do 68, xa 
coñecido dende inicios dos anos noventa na literatura de adultos e dende mediados desa década na infantil e xuvenil, e no poeta Carlos Negro (Lalín, 1970), autor da Xeración dos 90 que publicara no ano 2009 o poemario Makinaria, ao que lle seguirían, tamén para o lectorado adolescente, que ben coñece pola súa profesión como profesor de instituto, os denominados Penúltimas tendencias (2014) e Masculino singular (2016), ambos os dous cunha clara liña reivindicativa do papel da muller e na contra dos estereotipos de xénero.

O primeiro deles, Lourenzo González, obtivo o premio por Ceiba de $L u z$, unha novela de aventuras, cunha trama marcada pola intriga policial e cun achegamento ao fantástico lovecraftiano. O desencadeante da acción é o achado nunha tenda de antigüidades dunha pequena estatua humana, de ouro macizo e de fasquía precolombina, que motiva a organización da expedición Ceiba de Luz por parte da Universidade de Salamanca no mes de maio de 2007.

Comandado pola profesora de Historia Sandra Olivares, un grupo heteroxéneo formado por dezaoito persoas, especialistas en moi variadas disciplinas (historia, xeografía, topografía, botánica, medicina, culturas e linguas indíxenas, xornalismo, informática, cociña...) embarcarase na aventura de chegar ao mítico El Dorado a través da selva amazónica no Perú. Aí, no curso alto do río Marañón, tentarán descubrir as culturas taimahuara e arapanac, ás que se lles atribúe a peza escultórica atopada. A prolongada convivencia na antiga cidade de Haripari, poboada por uns seres humanos pasivos e melancólicos que os membros da expedición alcuman como «pasmóns», acabará provocando liortas, intrigas e traizóns, pero tamén relacións de amizade, amoríos e morte.

Ao longo de trinta capítulos, un narrador omnisciente conduce o lectorado, de xeito lineal e con extrema axilidade, até un final sorprendente neste relato que conta cunha boa dosificación da intriga, a viveza dos diálogos, unha atinada evolución psicolóxica dos personaxes e tamén pola vizosidade das descricións.

A concesión do galardón a Carlos Negro, por Aplicación instantánea (2018), foi unha grata sorpresa, pois foi a primeira vez, e única até o momento, que o Jules Verne recaeu nun poemario. Nel, a través do xogo 
de máscaras de diferentes avatares, faise unha análise crítica e plural das relacións humanas no mundo contemporáneo, mais tamén crítica social a diferentes cuestións sociais (por exemplo, critícase a excesiva presenza do cultivo do eucalipto en Galicia), así como a posta en valor da figura feminina, e o seu empoderamento, e da cultura e lingua galegas. Aplicación instantánea introduce con orixinalidade a importancia na sociedade actual das pantallas e as novas tecnoloxías con versos de alta calidade literaria, unha linguaxe vigorosa e rica e un discurso potente, apelativo e de intervención que non deixa a ninguén indiferente, tal como sinalaron os membros do xurado no momento do fallo do premio.

Finalmente a gañadora máis recente do Jules Verne foi Enma Pedreira (A Coruña, 1978), narradora, aínda que fundamentalmente poeta, que se estrea na Literatura Infantil e Xuvenil con Os corpos invisibles, texto presentado baixo o lema "Prometea". A narración, a medio camiño entre a novela histórica e a metaliteratura, ten como protagonista as mulleres. Dende a ollada dunha moza de quince anos que traballa dende os oito anos nunha fábrica téxtil de Londres en plena Revolución industrial, o relato achégase á realidade das nenas escravas que forman parte da produción en cadea, mais tamén á realidade dunha muller de clase alta, unida a aquela outra escritora da primeira novela de terror da modernidade, Frankestein, e a elas, na busca pola liberdade e polo recoñecemento que a todas se lles nega. Un relato con humor e crítica social que dá conta da desigualdade de clases, das discriminacións e de violencias por mor do xénero.

\title{
A modo de conclusión: a pertinencia do emprego nas aulas galegas das obras premiadas co Jules Verne
}

\author{
Ten sinalado Gomes (2012: 12) que
}

Não é possível promover a leitura sem um conhecimento da História literária, dos rumos passados e actuais, das diferentes modalidades genológicas patentes na escrita para crianças e jovens, bem como dos caminhos percorridos pela ilustração. Não é possível, enfim, promover a leitura sem ler - obviedade que qualquer leitor julgaria dispensável, mas que, paradoxalmente ou talvez não, importa continuar a enfatizar nos tempos que correm. Tão pouco é possível mediar a leitura sem recurso prévio ou concomitante a um discurso crítico produzido por estudiosos e investigadores - e não apenas promovido da espuma mediática 
e blogosférica -, e sem um saber mínimo sobre o panorama diacrónico desta criação literária e artística, o qual permita relativizar juízos apressados sobre o presente e suas pretensas inovações, e avaliar os retrocessos que nele também, por vezes, se verificam.

Neste senso botar man de obras galardoadas co Premio Jules Verne, todas elas publicadas na emblemática colección "Fóra de xogo" de Edicións Xerais de Galicia, pode axudar o mediador na selección de obras de calidade, avalada esta pola concesión dun recoñecemento no que participan profesionais da crítica, e afastadas da "espuma mediática e blogosférica" á que moitas veces o mediador ou mediadora pouco informado está tentado a acudir.

No que á autoría se refire, o premio Jules Verne permítelle ao lectorado o achegamento a escritoras e escritores de diferentes xeracións da historia da Literatura Infantil e Xuvenil galega, seguindo as marcadas en Roig (2015). Así, a xeración que maior presenza tivo neste premio até o momento é a Xeración dos 90, representada, como se viu, por Jaureguizar, Alfaya, Carré, Eduardo Santiago e Carlos Negro. Con todo esta é seguida de preto polas integrantes da Xeración Google, representada por Rosa Aneiros, Andrea Maceiras, Iria Misa e Emma Pedreira, e sendo anecdótica a presenza da Xeración do 68, con Marilar Aleixandre e Manuel Lourenzo González como expoñentes. O comentado deixa intuír a forza coa que as novas voces tratan de facerse un oco no panorama literario infantil e xuvenil galego. Voces novas ou xa asentadas no sistema literario que aquelas persoas que dan aulas ou se preparan para dalas deberían coñecer e mesmo recomendar aos compañeiros e discentes.

Así mesmo, a selección de escritores e escritoras resultante de estabelecer o criterio de obtención do Jules Verne permite observar como o achegamento da autoría masculina ou feminina a este galardón é practicamente parello, aínda que a balanza poida inclinarse minimamente cara a produción de autoría feminina. Desta maneira, dun total de once obras, seis delas débense a mulleres (Alfaya, Aleixandre, Aneiros, Maceiras, Misa e Pedreira) e cinco, a homes (Jaureguizar, Carré, Eduardo Santiago, Manuel Lourenzo González e Carlos Negro).

En canto ás temáticas, todas as obras gañadoras ofrecen novas maneiras de aproximarse a asuntos xa presentes con anterioridade na Literatura 
Infantil e Xuvenil galega ou, sobre todo, temas con pouca ou ningunha traxectoria nesta. Pénsese na recuperación da memoria histórica por parte de protagonistas, normalmente, situados na adolescencia; a indixencia; a violencia de xénero; a violencia sexual; a violencia económica; trastornos alimenticios; novas tecnoloxías; a loita por ver recoñecidos os logros científicos e intelectuais das mulleres fronte á apropiación que deles fixo o patriarcado ao longo da historia etc. Asuntos moitas veces abordados dende a ollada feminina ou mesmo feminista e na liña das esixencias estabelecidas no DECRETO 86/2015, do 25 de xuño, polo que se establece o currículo da educación secundaria obrigatoria e do bacharelato na Comunidade Autónoma de Galicia.

As cuestións abordadas neste corpus, moitas veces en plena actualidade, favorecen, coa axuda das Tecnoloxías da Información e da Comunicación, a realización de booktrailers e bitácoras que permiten responder dunha maneira máis amena a varios dos bloques de contido nos que se estrutura a materia Lingua Galega e Literatura na Educación Secundaria Obrigatoria e no Bacharelato, a saber: "Comunicación oral. Escoitar e falar", "Comunicación escrita. Ler e escribir", "Funcionamento da lingua" ou "Lingua e sociedade".

En definitiva, o Premio Jules Verne de Literatura Xuvenil, e as obras nel galardoadas e publicadas na colección "Fóra de xogo", confírmase como un espazo lector para as persoas adolescentes, non só do xénero narrativo, senón tamén de poesía, en lingua galega; unha aposta que todo mediador ou interesado na Literatura Infantil e Xuvenil debe coñecer e que se pon en relación co bloque de contido "Educación literaria"; un lugar no que a arte, por medio das imaxes das cubertas dos libros, tamén está presente e pode axudar a educar artisticamente.

Marta Neira Rodríguez

ICE-Universidade de Santiago de Compostela/ Centro Ramón Piñeiro para a Investigación en Humanidades

\section{Bibliografía}

Aleixandre, Marilar. 2008. A cabeza de Medusa. Vigo: Edicións Xerais de Galicia.

Alfaya, An. 2007. Illa Soidade. Vigo: Edicións Xerais de Galicia. 
Aneiros, Rosa. 2009. Ás de bolboreta. Vigo: Edicións Xerais de Galicia.

Carré, Héctor. 2011. Febre. Vigo: Edicións Xerais de Galicia.

Fernández Vázquez, Mar. 2015. "Febre polo volframio durante a Segunda Guerra Mundial", en De como a Literatura para a Infância e a fuventude «é chamada à guerra». Reflexões sobre os conflitos bélicos na Galiza e em Portugal /De como a Literatura para a Infancia e a Xuventude «é chamada á guerra». Reflexións sobre os conflitos bélicos en Galicia e Portugal (coords. Mar Fernández, Ana Cristina Macedo, Isabel Mociño e Ana Margarida Ramos). Porto: Tropelias\&Companhia/inED (Centro de Investigação e Inovação em Educação) - ESE-IP Porto (Portugal), "Estudos e Notas", pp. 191-207.

Ferreira Boo, Carmen. 2017. "Rompendo cos estereotipos de xénero: a personaxe de Carmucha en Febre, de Héctor Carré”, en Guerras mundiais na Literatura Infantil e Xuvenil galega. Roles femininos (coord. Eulalia Agrelo Costas). Santiago de Compostela: USC-LITER21.

Gomes, José António. 2012. "Introdução", en Tendências contemporáneas da literatura portuguesa para a infancia e juventude (Ana Margarida Ramos). Porto: Tropelias/ Companhia.

Jaureguizar, Santiago. 2006. A cova das vacas mortas. Vigo: Edicións Xerais de Galicia.

Lourenzo González, Manuel. 2017. Ceiba de Luz. Vigo: Edicións Xerais de Galicia.

Maceiras, Andrea. 2015. Europa Express. Vigo: Edicións Xerais de Galicia.

Misa, Iria. 2016. Xa non estou aquí. Vigo: Edicións Xerais de Galicia.

Mociño, Isabel. 1 decembro 2014. “A novela 'O gran reino', o xiro ó redor da infelicidade”, en El Correo Gallego, p. 46, https://www.elcorreogallego.es/portada/ ecg/novela-gran-reino-xiro-redor-da-infelicidade/idEdicion-2014-12-01/idNoticia-903503/ [Consulta: 01/09/2019].

Negro, Carlos. 2018. Aplicación instantánea. Vigo: Edicións Xerais de Galicia.

Neira, Marta. 18 xuño 2017. “Ausencias que magoan”, en El Correo Gallego, p. 4, https://www.elcorreogallego.es/tendencias/el-correo2/ecg/as-ausencias-magoan/idEdicion-2017-06-18/idNoticia-1060856/ [Consulta: 01/09/2019].

Pedreira, Emma. 2019. Os corpos invisibles. Vigo: Edicións Xerais de Galicia.

Pena, Montse. 2007. “Arquipélago desolador”, en Tempos Novos, n. o 5, p. 14. 
Puñal, Belén. 2009. "A palabra violada e o poder da reescrita", en Tempos Novos, "Protexta", n. 9 (inverno 08/09), "proPostas", p. 9.

Roig, Blanca-Ana. 1995-2017. Informes de literatura. Santiago de Compostela: Centro Ramón Piñeiro para a Investigación en Humanidades.

Roig, Blanca-Ana. 2015. Historia da Literatura Infantil e Xuvenil Galega. Vigo: Edicións Xerais de Galicia.

Santiago, Eduardo. 2014. O Gran Reino Vigo: Edicións Xerais de Galicia.

Senín, Xavier. 2009. "A cabeza de Medusa”, en Malasartes. Cadernos de Literatura para a Infância e a fuventude, n. ${ }^{\circ}$ 18, pp. 80-82.

Soto, Isabel. 2008. "Onte e hoxe: o mito de Medusa", en LG3, http://culturagalega.gal/lg3/extra_recension.php?Cod_extrs=1856\&Cod_prsa=93\&Cod_ prdccn=1503 [Consulta: 01/09/2019].

Soto, Isabel. 2010. "Ás de bolboreta, de Rosa Aneiros", en Malasartes. Cadernos de Literatura para a Infância e a Fuventude, n. ${ }^{\circ}$ 20, pp. 80-81.

Soto, Isabel. 22 novembro 2011. "A novela 'Febre', como si fora unha película do oeste”, El Correo Gallego, p. 50, https://www.elcorreogallego.es/galicia/ecg/novela-febre-fora-unha-pelicula-do-oeste/idEdicion-2011-11-22/idNoticia-714509/ [Consulta: 01/09/2019].

Soto, Isabel. 2015. "A novela 'Febre', como si fora unha película do oeste”, en Libros galegos de onte e boxe para a nenez e a mocidade (2010-2015) (coords. Blanca-Ana Roig Rechou e Isabel Mociño González). Santiago de Compostela: Universidade de Santiago de Compostela, servizo de Publicacións da Universidade de Santiago de Compostela/Instituto de Ciencias da Educación, pp. 64-65. 